\title{
Deoxygenation of oleic acid methyl ester in FCC process conditions over protonated and sodium exchanged $\mathrm{Y}$ and ZSM-5 zeolites
}

Jose Fernando Padilha

Universidade Federal da Bahia

Roger Frety

Universidade Federal da Bahia https://orcid.org/0000-0002-4532-2105

\section{Alane P. Santos}

Universidade Federal da Bahia

Luiz A. M. Pontes

Universidade Federal da Bahia

Marilia Ramalho Santos

Universidade Federal de Pernambuco

\section{Santiago Arias}

Universidade Federal de Pernambuco

Jose Geraldo Andrade Pacheco ( $\nabla$ jose.pacheco@ufpe.br)

Universidade Federal de Pernambuco https://orcid.org/0000-0002-8812-5021

\section{Research Article}

Keywords: Biodiesel, cracking, co-processing, fast pyrolysis, hydrocarbons, zeolite

Posted Date: March 11th, 2021

DOl: https://doi.org/10.21203/rs.3.rs-224425/v1

License: (a) This work is licensed under a Creative Commons Attribution 4.0 International License.

Read Full License

Version of Record: A version of this preprint was published at Waste and Biomass Valorization on June 27th, 2021. See the published version at https://doi.org/10.1007/s12649-021-01505-y. 


\section{Abstract}

One way to take advantage from out of specification biodiesel and waste from biodiesel tank bottom drainage is to co-process them in a fluidized catalytic cracking (FCC) unit. The present work deals with the cracking of oleic acid methyl ester (OAME) as a biodiesel model, under conditions close to that of FCC process over ZSM-5 and Y zeolites, either in protonated or sodium forms, for the production of deoxygenated compounds. Catalytic fast cracking of OAME pre-adsorbed on the catalyst surface was performed, with a catalyst:OAME mass ratio of $10: 1$ in a micro-pyrolysis system at $650^{\circ} \mathrm{C}$, coupled to a GC/MS for on line analysis of the products. Results show that the cracking of OAME without a catalyst favored the formation of linear alkenes and polyenes. Fast cracking of OAME over HZSM-5 and HY acidic zeolites led to the production of aromatics, due to hydrogen transfer. Cracking over NaY and HY zeolites produced remarkable amounts of ramified saturated hydrocarbons. The formation of alkylated hydrocarbons was not significant over ZSM-5 zeolite probably due to a small pore size of this zeolite. $\mathrm{NaY}$ catalyst favored the production of hydrocarbons in the range of kerosene (C8-C12). Low acidic zeolites favored the production of non-aromatic hydrocarbons. Product distribution was affected by catalyst shape selectivity and acidity. These results show that residues from the biodiesel chain can be directly co-processed in FCC units to obtain high value hydrocarbons, mainly in the jet fuel and gasoline ranges.

\section{Statement Of Novelty}

This work shows that oleic acid methyl ester as a model of residues from off-spec biodiesel and waste from biodiesel tank bottom drainage can be directly co-processed in a FCC unit, using ZSM- 5 and $Y$ zeolites as catalysts in $\mathrm{H}$ - and Na-form. The use of such residues in FCC process can promote the production o high value hydrocarbons, mainly in the jet fuel and gasoline ranges. These results may be of great interest to the growing market for renewable jet fuel since the aviation industry is committed to reduce $\mathrm{CO} 2$ emissions towards zero net carbon emissions. To the best of our knowledge, such a systematic study has not been reported yet.

\section{Introduction}

The emission of greenhouse gases from the high consumption of fossil fuels has recently been the cause of the hottest years and extreme weather events [1]. The use of biofuels has increased significantly to attain a sustainable economy and independence from fossil sources. The use of biodiesel as a diesel additive requires a rigorous quality control of this biofuel [2-3]. Biodiesel is subjected to chemical modification due to the double bonds of the methyl esters with one, two or three $\mathrm{C}=\mathrm{C}$ which can be easily oxidized. The chemical modifications of the biodiesel can be due to storage conditions such as exposure to air, humidity, light and temperature or to the presence of metals that have a catalytic activity for oxidation or polymerization reactions. The oxidized products are organic acids, hydroperoxides and aldehydes that cause corrosion problems to engine [4-5]. 
Polymerization reactions can produce gums, generating solid deposits in pumps and filters leading to engine operation problems. These products as well as microbial growth affect the quality properties of the biodiesel [6]. Finally, a limited quality biodiesel can appear when problems in the production process lead to the formation of an off-spec product with excess impurities such as soaps, glycerol or catalyst [7-8]. Another concern is the addition of an antioxidant to avoid the degradation of biodiesel.

Antioxidants may affect the clean-burning characteristic of biodiesel. The addition of up to $1000 \mathrm{ppm}$ of different kinds of commercial antioxidants led to the increase of hydrocarbons and $\mathrm{CO}$ emissions when blends of $20 \mathrm{vol} \%$ of biodiesel in diesel are burned in a diesel engine [9]. Then, off-spec biodiesel and waste from biodiesel tank bottom drainage become a feedstock candidate for deoxygenated biofuels production.

The thermal cracking of methyl esters of canola and soybean oils, at $440^{\circ} \mathrm{C}$, was studied by Luo et al [10] in a Parr type reactor, under autogenous pressure or hydrogen. Whereas the vegetable oil transformations produced as cracked products some fatty acids, alkanes and alkenes, the esters transformation produced small chain esters, alkanes and alkenes, without large differences between the various yields. These authors also showed that soybean oil and esters produced lighter products, due to a higher unsaturation of the carbon chain fatty acids, increasing the number of C-C bonds able to crack. Seames et al [11], of the same research group, studied the thermal conversion of long chain esters and suggested that cracking is an excellent way to obtain esters with a smaller carbon chain, resulting in better physical properties for potential kerosene type fuel. They needed, however, a distillation step at $300^{\circ} \mathrm{C}$, to decrease the residual oxygen content of the whole bio-oil obtained.

Hydrodeoxygenation (HDO) of methyl esters was also reported in the presence of supported metal catalyst. Han et al. [12] studied the HDO of methyl stearate diluted in hexane at $270^{\circ} \mathrm{C}$, under $16 \mathrm{bar} \mathrm{H}_{2}$ over $5 \% \mathrm{Pd} / \mathrm{BaSO}_{4}$, obtaining $99 \%$ conversion and $97 \%$ heptadecanoate selectivity that corresponds to diesel range. Dhillon and Vasudevan studied the deoxygenation of methyl oleate and commercial biodiesel over WO3/Y-Al2O3 and Ni-WO3/Y-Al2O3 catalysts [13]. According to Bezergianni et al. [14], the NiMo catalyst favors complete hydrodeoxygenation of glycerol tristearate producing $\mathrm{C} 18$ and $\mathrm{C} 3$ alkanes $+6 \mathrm{H}_{2} \mathrm{O}$, in a reaction more hydrogen-consuming than hydrodecarboxylation favored by NiW catalyst, producing $\mathrm{C} 17$ and $\mathrm{C} 3$ alkanes $+3 \mathrm{CO}_{2}$. However, these $\mathrm{HDO}$ processes consume a large amount of hydrogen and require expensive high pressure hydrogen facilities.

Deoxygenation of fatty esters can be performed without hydrogen consumption over acidic and metal catalysts. The deoxygenation of methyl octanoate on acidic H-ZSM5 produced C1-C7 hydrocarbons, with significant amounts of aromatics. Octanoic acid and 8-pentadecanone were formed as primary products from the hydrolysis of methyl octanoate, followed by condensation [15]. Bayat et al. [16] studied the cracking of canola oil methyl ester on $\mathrm{HZSM}-5$ at $375^{\circ} \mathrm{C}$, and obtained $75 \%$ of liquid products containing $57 \%$ of aromatics, mainly xylenes, toluene and C9 aromatics. Chiappero et al. [17] studied the deoxygenation of methyl octanoate over $\mathrm{Pt} / \mathrm{SiO} 2$ catalyst under helium at $350^{\circ} \mathrm{C}$, in a reactive distillation system. They obtained $56 \%$ C7 alkanes and $40 \%$ C7 alkenes. Sancheti [18] studied the deoxygenation of 
methyl palmitate diluted in n-hexane over a Ni5Mo10K/TS-1 (titanosilicate) catalyst at $380^{\circ} \mathrm{C}$, obtaining $29 \%$ conversion and selectivity of $87 \%$ to $\mathrm{C} 15$ alkenes and $8 \%$ to $\mathrm{C} 15$ alkanes.

To lower the cost, a deoxygenation process can take place in an existing industrial facility such as the FCC process. FCC is a catalytic process transforming large molecules of petroleum feedstocks to lighter ones, compatible with gasoline, kerosene and diesel fuels. Co-processing of FCC petroleum feedstocks with oxygenated molecules, such as those obtained from biomass processing [14, 19-20] and triglycerides from vegetable oils [21], has been reported. Results showed that up to 10 mass \% of oxygenated molecules can be added to petroleum cuts without decreasing the yields of useful products [19]. During the cracking process, FCC catalysts that contain acidic zeolites as active phase are permanently deactivated and regenerated. The addition of controlled amounts of oxygenated molecules during cracking seems ineffective in decreasing the lifetime of the catalysts $[19,21]$. Therefore, it can be important to further study the cracking of other oxygenated molecules such as fatty acid ester under conditions close to that of FCC process [22].

To simulate a bench-scale FCC process, a fixed-bed microactivity test (MAT) unit is generally used. However, this type of reactor presents differences in comparison to the industrial process related to (i) the fluid dynamics of the fluidized reactor compared to fixed bed; (ii) the short contact times that in the FCC reactor vary from 2 to $10 \mathrm{~s}$; and (iii) the stripping of the reaction products in the MAT system [23]. In a preceding study, some of us [24] suggested that the micropyrolysis of fatty compounds preadsorbed on catalyst surface can be used to screen some catalytic properties, as catalytic micropyrolysis generates a large spectrum of organic products. As the experimental conditions used were close to those used in FCC process, with high heating rates, and a catalyst:feed mass ratio close to 9 , such procedure can in part simulate what occurs in a FCC riser. The present work aims at studying deoxygenation of oleic acid methyl ester close to FCC conditions in absence or presence of $\mathrm{Y}$ and ZSM-5 zeolites, in both protonated and sodium forms, to investigate the formation of deoxygenated products and their distribution. $Y$ zeolites and ZSM-5 are typical zeolites used in FCC catalysts.

\section{Experimental}

\subsection{Catalysts}

Starting catalysts samples were $\mathrm{NH}_{4} \mathrm{ZSM}-5(\mathrm{Si} / \mathrm{Al}=15)$ and $\mathrm{NH}_{4} \mathrm{Y}(\mathrm{Si} / \mathrm{Al}=6)$ materials from Zeolyst, in powder form. These samples were heat treated at $600^{\circ} \mathrm{C}$ under static air to obtain the acid forms HZSM5 and $\mathrm{HY}$, respectively. These new samples were then exchanged with aqueous solution of sodium nitrate $\left(5 \mathrm{~mol} \mathrm{~L}^{-1}\right)$ for one hour, washed with deionized water to remove nitrate ions, dried at $110^{\circ} \mathrm{C}$ and heat treated under static air at $500{ }^{\circ} \mathrm{C}$ for 3 hours. This exchange procedure was repeated three times. Final samples are referred to as NaZSM- 5 and NaY.

\subsection{Mixtures of oleic acid methyl ester and catalyst}


Oleic acid methyl ester (Sigma Aldrich) was impregnated onto $\mathrm{H}$ - and Na-zeolites, after drying at $110^{\circ} \mathrm{C}$, by dropping micro amounts of the pure organic molecule onto powdered zeolites, under constant manual mixing. The mass ratio of catalyst:oleic acid methyl ester was 10:1. At the end of this process, samples were still in their initial powder form. These impregnated samples are thereafter referred to $\mathrm{OAME} /$ catalyst, catalyst representing $\mathrm{H}$ - or Na-zeolite.

\subsection{Pyrolysis experiments}

Cracking experiments have been performed in a micropyrolyzer Pyroprobe 5200 CDS Analytical set up described in previous works [25-26]. The cracking temperature was fixed at $650^{\circ} \mathrm{C}$ for 15 seconds, which is higher than the FCC raiser feed temperature $\left(500^{\circ} \mathrm{C}\right)$ and lower than the temperature of the incoming FCC regenerated hot catalyst $\left(715^{\circ} \mathrm{C}\right)$ [27]. The heating rate of the pyrolysis space, by a platinum coil resistance, was estimated to be $1,000^{\circ} \mathrm{C} \mathrm{min}-1$. The sample mass of catalyst impregnated with OAME was about $1.5 \mathrm{mg}$. The sample was placed in a quartz tube, between two quartz wool plugs. The sample was submitted to a helium flow rate of $150 \mathrm{~mL} \mathrm{~min}^{-1}$. Cracked products (up to 400 compounds) and untransformed feed were separated in a GC/MS apparatus Shimadzu QP2010. The GC program started at $45{ }^{\circ} \mathrm{C}$ for $5 \mathrm{~min}$, heating ramp of $4{ }^{\circ} \mathrm{C} \mathrm{min}-1$, and final temperature of $280^{\circ} \mathrm{C}$. Split injector temperature was $250{ }^{\circ} \mathrm{C}$ and split ratio was $30: 1$. GC column was a DB-5MS (30 m x $\left.0.25 \mathrm{~mm} \times 0.2 \mu \mathrm{m}\right)$. The temperature of MS interface was $290^{\circ} \mathrm{C}$ and that of the ion source was $250^{\circ} \mathrm{C}$. MS operated in scan mode with $\mathrm{m} / \mathrm{z}$ range of $40-400$. Deoxygenated products were identified with the help of the NIST data library with similarity equal to or higher than $90 \%$. A standard mixture of hydrocarbons was used to help identify the products: PIANO Mix from Sigma-Aldrich/Supelco, Bellefonte, PA, USA. Due to a large number of products, the deoxygenated compounds were grouped by summing peak areas of specific molecules or molecule families. To classify the different families of compounds, the products were first separated as unidentified, oxygenated and deoxygenated compounds, i.e. hydrocarbons. Deoxygenated molecules were further separated as alkanes, alkenes, polyenes and aromatic compounds. Among saturated and monounsaturated hydrocarbons, linear, cyclic and ramified molecules were further associated. Separation between single benzene ring and molecules with multiple benzene rings was also considered.

Deoxygenated molecules were also associated in three families of hydrocarbons, C3-C7, C8-C12 and $\mathrm{C} 12+$ to estimate the type of products able to be added or upgraded to gasoline, kerosene or diesel cuts.

\section{Results And Discussion}

In all cases of oleic acid methyl ester (OAME) cracking, between 20 to $30 \%$ of pyrogram total area was due to unidentified and products with similarity identification between 60 and $75 \%$. This value is higher than that of unidentified products estimated when cracking myristic acid and palmitic acid as model molecules [26, 28]. This fact implies a more complex mechanistic scheme during cracking of unsaturated fatty molecules $[25,29]$ when compared to the scheme retained during cracking of saturated fatty acids which is attributed essentially to decarboxylation and decarbonylation reactions, in agreement with the literature data [30-33]. In the present case, a complete deoxygenation of the oleic acid methyl ester (OAME) was not obtained. But, in their majority, the remaining oxygenated compounds were susceptible 
to further decomposition when the contact time between catalyst and reactant and/or intermediate products was increased. Therefore, it was expected that the general trends in the product distribution observed in this work would be maintained with a higher degree of decomposition of the feed.

\subsection{Cracking of pure oleic acid methyl ester in absence of catalyst}

Oleic acid methyl ester C18:1 (OAME) pyrogram after cracking at $650^{\circ} \mathrm{C}$ in absence of catalyst is presented in Fig. 1. The pyrogram can be divided into two main domains. The left part region, below retention time close to $33 \mathrm{~min}$, where peaks rather well separated of limited size appear; and the right part, above retention time of $33 \mathrm{~min}$, where peaks, poorly separated, of important size are observed. The larger peak in this second region (retention time close to $50 \mathrm{~min}$ ) is due to untransformed OAME. Product classes reported in Table 1 show that thermal cracking of OAME at $650^{\circ} \mathrm{C}$ produced only $4.3 \%$ of deoxygenated compounds, essentially associated to peaks below retention time of $33 \mathrm{~min}$. In the right part of the pyrogram, many oxygenated and unidentified products are present. Along all the pyrogram, a large amount of carboxylic acid methyl esters was observed (75.1\%), i.e. methyl esters of C2 to C18 saturated and unsaturated carboxylic acids. This result implies that under these conditions, cracking of OAME and methyl esters of lower chain length can occur not only close to the carboxylate position, but also within the hydrocarbon chain, probably in the beta position of the $\mathrm{C}=\mathrm{C}$ bond. The presence of all chain lengths between the $\mathrm{C} 2$ and $\mathrm{C} 19$ methyl esters suggests also an important migration of the $\mathrm{C}=\mathrm{C}$ double bond position before cracking occurs. Although the number of hydrocarbons $(\mathrm{HC})$ observed from pure OAME cracking is low, the $\mathrm{HC}$ production is much higher after cracking in presence of catalysts studied.

\subsection{Cracking of oleic acid methyl ester adsorbed on zeolites}

The cracking of OAME impregnated on zeolite catalysts at $650^{\circ} \mathrm{C}$ presented a higher degree of reaction than the cracking of pure OAME. Figure 1 shows together with that of pure OAME, the pyrograms of OAME/HY, OAME/NaY, OAME/HZSM-5 and OAME/NaZSM-5. The cracking of OAME in contact with zeolites presented a higher degree of transformation than the cracking of pure OAME. The quantitative results are shown in Table 1. The area \% of hydrocarbons varies from 24 to almost $40 \%$ in presence of catalysts while this value is only $4.3 \%$ for the cracking of OAME in absence of catalysts. Simultaneously, the number of oxygenated compounds decreased in the catalytic cracking. Therefore, both acidic and sodium zeolite catalysts helped the deoxygenation of OAME, in the same way they favored deoxygenated products as reported in the case of fatty acids cracking [24]. The number of produced hydrocarbons over $\mathrm{HY}$ and $\mathrm{NaY}$ was practically the same. However, the number of hydrocarbons over HZSM- 5 was much higher than over NaZSM-5, suggesting that the acid sites in HZSM-5 are more effective in producing the deoxygenation reactions. In all cases, the number of unidentified compounds is higher when cracking is performed in presence of catalyst, suggesting more complex reaction schemes. 
Table 1

Product family distribution after cracking of oleic acid methyl ester (OAME) at $650^{\circ} \mathrm{C}$, pure and in presence of NaZSM-5, HZSM-5, NaY and HY catalysts.

\begin{tabular}{|llll|}
\hline Catalyst & Unidentified & Oxygenated & Hydrocarbons \\
\hline Pure OAME & 11.2 & 84.5 & 4.3 \\
\hline OAME/NaZSM-5 & 18.1 & 57.4 & 24.5 \\
\hline OAME/HZSM-5 & 19.1 & 41.9 & 39.0 \\
\hline OAME/NaY & 36.1 & 26.4 & 37.5 \\
\hline OAME/HY & 15.7 & 45.1 & 39.2 \\
\hline
\end{tabular}

Table 2 summarizes a first association of hydrocarbon families obtained after cracking of OAME. In the case of pure OAME, cracking produced mainly linear alkenes, the majority of them being 1-alkenes. These alkenes are an important class of products in the cracking of saturated fatty acids, as the main decomposition mechanism is due to simple decarbonylation $[28,33]$. The second class of important products has been observed to be polyunsaturated molecules, including dienes, trienes and alkynes. In the presence of all catalysts, the cracking of OAME produced a high number of aromatics. Protonated catalysts HZSM- 5 and HY were more effective for aromatization than sodium catalysts NaZSM- 5 and $\mathrm{NaY}$, respectively. The second most important hydrocarbon family was that of alkenes in the case of NaZSM-5, HZSM-5 and NaY. In the case of HY, the second most important group was that of alkanes.

Table 2

Hydrocarbon family distribution after cracking at $650^{\circ} \mathrm{C}$ of oleic acid methyl ester (OAME), pure and in the presence of NaZSM-5, HZSM-5, $\mathrm{NaY}$ and HY catalysts.

\begin{tabular}{|lllll|}
\hline Catalyst & Alkanes & Alkenes & Polyenes & Aromatics \\
\hline OAME & 0.6 & 2.3 & 1.3 & 0.1 \\
\hline OAME/NaZSM-5 & 0.0 & 10.0 & 0.0 & 14.0 \\
\hline OAME/HZSM-5 & 2.1 & 13.1 & 1.6 & 22.2 \\
\hline OAME/NaY & 7.8 & 11.8 & 0.6 & 16.8 \\
OAME/HY & 12.7 & 3.6 & 2.1 & 20.0 \\
\hline
\end{tabular}

Table 3 details the distribution of saturated and unsaturated products. Whereas more linear alkanes appear in the case of OAME cracking over HZSM-5, the presence of ramified alkanes is remarkable when OAME cracking was performed over both $\mathrm{NaY}$ and $\mathrm{HY}$ zeolites. In the case of alkenes, whereas more linear alkenes appear with OAME/NaZSM-5 and OAME/HZSM-5, ramified alkenes show the highest content in the cracking with OAME/NaY, OAME/HZSM-5 and OAME/HY. Therefore, in a systematic way, $\mathrm{Y}$ type zeolite presents a more important alkylation property than ZSM-5 type zeolite, probably due to acid 
sites of stronger strength or in greater numbers [34]. In fact, although acidity measurements were difficult to obtain under the present experimental conditions, an estimation based on Si/Al ratio [35] suggests that the number of acid sites is probably two times more important with $\mathrm{HY}$ (with $\mathrm{Si} / \mathrm{Al}=6$ ) than with $\mathrm{HZSM}-5$ (with $\mathrm{Si} / \mathrm{Al}=15$ ). The higher the Al content, the higher the acidity. Another explanation is the occurrence of shape selectivity. The pore size of the Y zeolite (7.4 Á) is larger than that of ZSM-5 (5.1-5.6 ̊́) zeolite, enabling alkylation reactions which require more space inside the porous structure [36-37]. It is also important to recall that 1 -alkenes represent more than $50 \%$ of all alkenes in the case of thermal cracking of pure OAME and cracking in presence of NaZSM-5. On the contrary, in the other cases, small amounts of 1-alkenes are identified, when present. All three $\mathrm{HZSM}-5, \mathrm{Na} / \mathrm{Y}$ and $\mathrm{HY}$ catalysts favor the formation of cyclic and internal linear alkenes, eventually alkylated. These three zeolites show therefore a high capacity of isomerization, probably due to higher number of acidic sites existing on their surface. In the case of Y-based catalysts, the larger pore size compared to that of HZSM-5 may also favor molecules with higher kinetic diameter, i.e. ramified ones, as commented above.

Table 3

Distribution of alkane and alkene hydrocarbon families into linear, cyclic and ramified classes, after cracking at $650^{\circ} \mathrm{C}$ of oleic acid methyl ester (OAME), pure and in presence of NaZSM-5, HZSM-5, NaY and HY catalysts.

\begin{tabular}{|lllllll|}
\hline Catalyst & $\begin{array}{l}\text { Linear } \\
\text { Alkanes }\end{array}$ & $\begin{array}{l}\text { Cyclo- } \\
\text { Alkanes }\end{array}$ & $\begin{array}{l}\text { Ramified } \\
\text { Alkanes }\end{array}$ & $\begin{array}{l}\text { Linear } \\
\text { Alkenes }\end{array}$ & $\begin{array}{l}\text { Cyclo- } \\
\text { Alkenes }\end{array}$ & $\begin{array}{l}\text { Ramified } \\
\text { Alkenes }\end{array}$ \\
\hline OAME & 0.2 & 0.1 & 0.3 & 1.8 & 0.5 & 0.4 \\
\hline $\begin{array}{l}\text { OAME/NaZSM- } \\
5\end{array}$ & 0.0 & 0.0 & 0.0 & 7.4 & 1.5 & 2.6 \\
\hline OAME/HZSM-5 & 1.8 & 0.3 & 0.3 & 5.7 & 2.3 & 7.0 \\
\hline OAME/NaY & 0.5 & 2.3 & 7.2 & 2.1 & 1.6 & 9.6 \\
\hline OAME/HY & 0.4 & 1.3 & 12.2 & 0.3 & 0.9 & 3.3 \\
\hline
\end{tabular}

Table 4 presents the distribution of aromatic compounds. The formation of aromatics was not significant in the case of thermal cracking of OAME. On the contrary, as said above, the formation of aromatic molecules is very impressive when OAME is cracked over zeolite samples. HY and HZSM-5 zeolites showed a higher aromatization capacity than the sodium exchanged ones.

Whereas a high number of molecules containing a single benzene ring are present with OAME/NaZSM-5 and OAME/HZSM-5, molecules containing more than one benzene ring are identified in a significant way during the cracking of OAME adsorbed on $\mathrm{Y}$ type zeolites. In the case of OAME/HY, polyaromatic compounds with 3 benzene rings were detected, suggesting an important possibility of coking of this catalyst during cracking of OAME. The formation of mono aromatic hydrocarbons may be associated with the dehydrogenation of six carbon numbered cyclic alkanes and alkenes [32,38]. Polyaromatic hydrocarbons, on the other hand, are formed through the polymerization and dehydrogenation of mono alkyl aromatics [23] and alternatively through an intramolecular radical cyclization mechanism [38]. It is 
known that polyaromatics are generally considered as potential precursors of coke [39-40]. This behavior, together with the hydrogenation properties shown by $Y$ type zeolite must be linked to strong acidic properties of $Y$ zeolite and to hydrogen transfer phenomena, leading on one hand to rather large number of saturated hydrocarbons, and on the other hand to strongly dehydrogenated polyaromatic molecules.

Table 4

Distribution of monoaromatic and polyaromatic product families after cracking at $650^{\circ} \mathrm{C}$ of oleic acid methyl ester (OAME), pure and in presence of NaZSM-5, HZSM-5, NaY and HY catalysts.

\begin{tabular}{|lll|}
\hline Catalyst & Monoaromatics & Polyaromatics \\
\hline OAME & 0.0 & 0.1 \\
\hline OAME/NaZSM-5 & 13.6 & 0.4 \\
\hline OAME/HZSM-5 & 17.4 & 4.8 \\
OAME/NaY & 9.3 & 7.5 \\
\hline OAME/HY & 12.3 & 7.7 \\
\hline
\end{tabular}

Figure 2 summarizes the quantities of hydrocarbons associated to the carbon chain numbers: C3-C7 (gaseous and gasoline) range, C8-C12 (kerosene) range and C12+ (diesel) range. Results show three features concerning product distribution: i) the number of products in the $\mathrm{C} 12+$ range is rather low, the majority of deoxygenated molecules in this range being aromatics in the case of OAME cracked over catalysts; ii) the C3-C7 range is more important in the case of ZSM-5 zeolites than in the case of $Y$ zeolites. It can be noted that with both Na-ZSM- 5 and H-ZSM-5, significant amount of propene is formed. This property has also been observed when cracking petroleum feedstock in the FCC process using ZSM5 in the catalyst formulation [41]. These results confirm that ZSM-5, during its cracking activity, has a higher capacity to promote the formation of small unsaturated molecules than Y zeolite; iii) with both ZSM-5 and Y zeolites, the presence of sodium induces a decrease in the formation of light products. This result also confirm that protonated zeolites promote the cracking reactions of oleic acid methyl ester towards light compounds.

The cracking of OAME over HZSM-5, NaY and HY led to the production of a large number of molecules in the range $\mathrm{C} 8 \mathrm{-C} 12$ (kerosene range), the best catalyst being $\mathrm{NaY}$. As aviation transport needs to strongly decrease its carbon emissions, with a possibility of zero net carbon emission by 2050 [42] the necessity to increase the production of green kerosene is mandatory. Then, the present work indicates that one possible way to increase the production of this fuel fraction can be through the addition of some residue biodiesel to the FCC cracking cuts. Other oxygenated molecules such as bio-oil and more probably fatty acids and triglycerides, due their molecular structure close to that of OAME can probably play an additional role in this increasing market. 


\section{Conclusions}

Catalytic cracking of oleic acid methyl ester (OAME), used as a model molecule of spoiled biodiesel waste, was performed in the presence of ZSM-5 and $Y$ zeolites, both in their acidic and sodium forms. The cracking of pure OAME, without catalyst, under conditions close to that of the FCC process produced mainly linear mono and poly alkenes. The cracking of OAME over HZSM-5 and HY zeolites promoted a high production of aromatics. Ramified saturated hydrocarbons distribution was remarkable when OAME cracking was performed over $\mathrm{NaY}$ and $\mathrm{HY}$ zeolites, indicating a promotion of alkylation reactions when compared to ZSM-5 with smaller pores. These results suggest that both shape selectivity and acidity, linked to hydrogen transfer play a role in the product distribution. $\mathrm{NaY}$ catalyst favored the production of hydrocarbons in the range of kerosene (C8-C12). These results may be of great interest to the market for renewable jet fuel since the aviation industry is committed to reduce $\mathrm{CO}_{2}$ emissions significantly in the coming years.

\section{Declarations}

\section{Acknowledgments and Funding}

We gratefully acknowledge financial support from FINEP, RECAT, National Council for Scientific and Technological Development, CNPq/Universal project 430921/2016-0, CNPq/INCT-EMA, PETROBRAS-ANPLITPEG contract 0050.0078506.12.9, BNB/FUNDECI project 059/2005, FACEPE, CAPES/PNPD and FAPESB. English revision by Sidney Pratt, Canadian, BA, MAT (The Johns Hopkins University), RSAdip (TEFL) (Cambridge University).

\section{References}

1. Atelge, M.R., Krisa, D., Kumar, G., Eskicioglu, C., Nguyen, D.D., Chang, S.W., Atabani, A.E., Al-Muhtaseb, A.H., Unalan, S.: Biogas production from organic waste: recent progress and perspectives. Waste Biomass Valor. 11, 1019-1040 (2020). https://doi.org/10.1007/s12649-018-00546-0

2. Ahmad, S., Kothari, R., Pathak, V.V., Pandey, M.K.: Fuel quality index: a novel experimental evaluation tool for biodiesel prepared from waste cooking oil. Waste Biomass Valori. 10, 2237-2247 (2019). https://doi.org/10.1007/s12649-018-0250-9

3. Silva, R.J.M.C.L., Tschoeke, I.C.P., Melo, J.C., Silva, J.P., Pacheco, J.G.A., Silva, J.M.F., Souza, T.P.C.: Comparison between experimental and simulated results of biodiesel production by reactive distillation and energetic assessment. Braz. J. Chem. Eng. 36, 351-359 (2019). https://doi.org/10.1590/0104-6632.20190361s20170266

4. Narayanasamy, B., Jeyakumar, N., Balasubramanian, D.: Effect of Star Anise as a Natural Antioxidant Additive on the Oxidation Stability of Lemon Grass Oil. Waste Biomass Valor. (2020). https://doi.org/10.1007/s12649-020-01218-8 
5. Singh, M., Singh, D.K., Gandhi, S.K., Sarin, A., Saini, S., Mahla, S.K., Gupta, A., Sandhu, S.S.: Effect of metal contaminants and antioxidants on the oxidation stability of argemone mexicana biodiesel: Experimental and statistical study. Waste Biomass Valor. 11, 6189-6198 (2020). https://doi.org/10.1007/s12649-019-00886-5

6. Xiao, M., Lin, D., Li, Z., Zhao, J., Long, X., Wu, Z.: Synthesis of Biodiesel from Waste Cooking Oil by One-step Esterification and Its Structural Characterization. Waste Biomass Valor. 11, 2087-2100 (2020). https://doi.org/10.1007/s12649-018-0500-x

7. Souza, T.P.C., Silva, R.J.M.C.L., Melo, J.C., Tschoeke, I.C.P., Silva, J.P., Pacheco, J.G.A., Silva, J.M.F.: Kinetic modeling of cottonseed oil transesterification with ethanol. React. Kinet. Mech. Catal. 128, 707-722 (2019). https://doi.org/10.1007/s11144-019-01661-2

8. Cardoso, C.C., Cavalcanti, A.S., Silva, R.O., Junior, S.A., de Sousa, F.P., Pasa, V.M.D., Arias, S., Pacheco, J.G.A.: Residue-Based CaO Heterogeneous Catalysts from Crab and Mollusk Shells for FAME Production Via Transesterification. J. Braz. Chem. Soc. 31, 756-767 (2020). https://doi.org/10.21577/0103-5053.20190240

9. Fattah, I.M.R., Masjuki, H.H., Kalam, M.A., Mofijur, M., Abedin, M.J.: Effect of antioxidant on the performance and emission characteristics of a diesel engine fueled with palm biodiesel blends. Energ. Convers. Manage. 79, 265-272 (2014). https://doi.org/10.1016/j.enconman.2013.12.024

10. Luo, Y., Ahmed, I., Kubátová, A., Štáávová, J., Aulich, T., Sadrameli, S.M., Seames, W.S.: The thermal cracking of soybean/canola oils and their methyl esters. Fuel Process. Technol. 91, 613-617: (2010). https://doi.org/10.1016/j.fuproc.2010.01.007

11. Seames, W., Luo, Y., Ahmed, I., Aulich, T., Kubatova, A., Št'ávová, J., Kozliak, E.: The thermal cracking of canola and soybean methyl esters: improvement of cold flow properties. Biomass Bionerg. 34, 939-946 (2010). https://doi.org/10.1016/j.biombioe.2010.02.001

12. Han, J., Sun, H., Ding, Y., Lou, H., Zheng, X.: Palladium-catalyzed decarboxylation of higher aliphatic esters: Towards a new protocol to the second generation biodiesel production. Green Chem. 12, 463467 (2010). https://doi.org/10.1039/B917690J

13. Dhillon, G.S., Vasudevan, P.T.: Deoxygenation of methyl oleate and commercial biodiesel over W and Ni-W Catalysts. Waste Biomass Valor. (2020). https://doi.org/10.1007/s12649-020-01146-7

14. Bezergianni, S., Dimitriadis, A., Kikhtyanin, O., Kubička, D.: Refinery co-processing of renewable feeds. Prog. Energy Combust. Sci. 68, 29-64 (2018). https://doi.org/10.1016/j.pecs.2018.04.002

15. Danuthai, T., Jongpatiwut, S., Rirksomboon, T., Osuwan, S., Resasco, D.E.: Conversion of methylesters to hydrocarbons over an H-ZSM5 zeolite catalyst. Appl. Catal., A. 361, 99-105 (2009). https://doi.org/10.1016/j.apcata.2009.04.001

16. Bayat, A., Sadrameli, S.M.: Conversion of canola oil and canola oil methyl ester (CME) to green aromatics over a HZSM-5 catalyst: a comparative study. RSC Adv. 5, 28360-28368 (2015). https://doi.org/10.1039/C5RA01691F

17. Chiappero, M., Do, P.T.M., Crossley, S., Lobban, L.L., Resasco, D.E.: Direct conversion of triglycerides to olefins and paraffins over noble metal supported catalysts. Fuel. 90, 1155-1165 (2011). 
https://doi.org/10.1016/j.fuel.2010.10.025

18. Sancheti, S.V., Yadav, G.D., Ghosh, P.K.: Synthesis and Application of Novel NiMoK/TS-1 for Selective Conversion of Fatty Acid Methyl Esters/Triglycerides to Olefins. ACS Omega. 5, 5061-5071 (2020). https://doi.org/10.1021/acsomega.9b03993

19. Pinho, A.R., de Almeida, M.B.B., Mendes, F.L., Ximenes, V.L., Casavechia, L.C.: Co-processing raw biooil and gasoil in an FCC unit. Fuel Process. Technol. 131, 159-166: (2015). https://doi.org/10.1016/j.fuproc.2014.11.008

20. Lappas, A.A., Bezergianni, S., Vasalos, I.A.: Production of biofuels via co-processing in conventional refining processes. Catal. Today. 145, 55-62 (2009). https://doi.org/10.1016/j.cattod.2008.07.001

21. Büchele, M., Swoboda, M., Reichhold, A., Hofer, W.: Canola oil/glycerol mixtures in a continously operated FCC pilot plant and comparison with vacuum gas oil/glycerol mixtures. Chem. Eng. Process. 142, 107553 (2019). https://doi.org/10.1016/j.cep.2019.107553

22. Dupain, X., Costa, D.J., Schaverien, C.J., Makkee, M., Moulijn, J.A.: Cracking of a rapeseed vegetable oil under realistic FCC conditions. Appl. Catal. B. 72, 44-61 (2007). https://doi.org/10.1016/j.apcatb.2006.10.005

23. Melero, J.A., Clavero, M.M., Calleja, G., García, A., Miravalles, R., Galindo, T.: Production of biofuels via the catalytic cracking of mixtures of crude vegetable oils and nonedible animal fats with vacuum gas oil. Energy Fuels. 24, 707-717 (2010). https://doi.org/10.1021/ef900914e

24. Fréty, R., Santos, M.R., Padilha, J.F., Azevedo, A.F., Brandão, S.T., Pontes, L.A., Pacheco, J.G.A.: Flash pyrolysis of model compounds adsorbed on catalyst surface: A method for screening catalysts for cracking of fatty molecules. J. Anal. Appl. Pyrolysis. 109, 56-64 (2014). https://doi.org/10.1016/j.jaap.2014.07.013

25. Fréty, R., Santos, M.R., Sales, R.F., Silva, A.O.S., Barbosa, C.B.M., Pacheco, J.G.A.: Flash pyrolysis of oleic acid as a model compound adsorbed on supported nickel catalysts for biofuel production. J. Braz. Chem. Soc. 25, 2433-2443 (2014). https://doi.org/10.5935/0103-5053.20140270

26. Santos, M.R., Sales, R.F., Silva, A.O.S., Teixeira, C.M., Pacheco, J.G.A., Fréty, R.: Flash pyrolysis of myristic acid adsorbed on supported nickel catalysts for biofuel production. J. Therm. Anal. Calorim. 119, 1875-1885 (2015). https://doi.org/10.1007/s10973-014-4375-1

27. Gary, J.H., Handwerk, G.E., Kaiser, M.J.: Petroleum refining: technology and economics. CRC Press, Boca Raton (2007)

28. Santos, M.R., Arias, S., Padilha, J.F., Carneiro, M.C.N., Sales, E.A., Pacheco, J.G.A., Fréty, R.: Catalytic cracking of palmitic and oleic acids pre-adsorbed on y-alumina. Catal. Today. 344, 234-239 (2020). https://doi.org/10.1016/j.cattod.2019.04.005

29. Omidghane, M., Bartoli, M., Asomaning, J., Xia, L., Chae, M., Bressler, D.C.: Pyrolysis of fatty acids derived from hydrolysis of brown grease with biosolids. Environ. Sci. Pollut. Res. 27, 26395-26405 (2020). https://doi.org/10.1007/s11356-020-09041-3

30. Maher, M.K., Kirkwood, K.M., Gray, M.R., Bressler, D.C.: Pyrolytic decarboxylation and cracking of stearic acid. Ind. Eng. Chem. Res. 47, 5328-5336 (2008). https://doi.org/10.1021/ie0714551 
31. Lappi, H., Alén, R.: Production of vegetable oil-based biofuels-Thermochemical behavior of fatty acid sodium salts during pyrolysis. J. Anal. Appl. Pyrolysis. 86, 274-280 (2009).

https://doi.org/10.1016/j.jaap.2009.07.005

32. Asomaning, J., Mussone, P., Bressler, D.C.: Thermal deoxygenation and pyrolysis of oleic acid. J. Anal. Appl. Pyrolysis. 105, 1-7 (2014). https://doi.org/10.1016/j.jaap.2013.09.005

33. Arias, S., González, J.F., Sousa, L.V., Barbosa, C.B.M., Silva, A.O.S., Fréty, R., Pacheco, J.G.A.: Influence of $\mathrm{Ni} / \mathrm{Al}$ ratio on the fast pyrolysis of myristic acid when adsorbed on unsupported mixed oxides derived from layered double hydroxides. Catal. Today (2020).

https://doi.org/10.1016/j.cattod.2020.07.028

34. Mante, O.D., Agblevor, F.A., Oyama, S.T., McClung, R.: Catalytic pyrolysis with ZSM-5 based additive as co-catalyst to Y-zeolite in two reactor configurations. Fuel. 117, 649-659 (2014). https://doi.org/10.1016/j.fuel.2013.09.034

35. Kotrel, S., Rosynek, M.P., Lunsford, J.H.: Quantification of acid sites in H-ZSM-5, H- $\beta$, and HY zeolites. J. Catal. 182, 278-281 (1999). https://doi.org/10.1006/jcat.1998.2339

36. Denayer, J.F., Souverijns, W., Jacobs, P.A., Martens, J.A., Baron, G.V.: High-temperature low-pressure adsorption of branched $\mathrm{C}_{5}-\mathrm{C}_{8}$ alkanes on zeolite Beta, ZSM-5, ZSM-22, zeolite $\mathrm{Y}$, and mordenite. J. Phys. Chem. B. 102, 4588-4597 (1998). https://doi.org/10.1021/jp980674k

37. Mihalcik, D.J., Mullen, C.A., Boateng, A.A.: Screening acidic zeolites for catalytic fast pyrolysis of biomass and its components. J. Anal. Appl. Pyrolysis. 92, 224-232 (2011). https://doi.org/10.1016/j.jaap.2011.06.001

38. Kubátová, A., Št'ávová, J., Seames, W.S., Luo, Y., Sadrameli, S.M., Linnen, M.J., Baglayeva, G.V., Smoliakova, I.P., Kozliak, E.I.: Triacylglyceride thermal cracking: Pathways to cyclic hydrocarbons. Energy Fuels. 26, 672-685 (2012). https://doi.org/10.1021/ef200953d

39. Guisnet, M., Magnoux, P.: Organic chemistry of coke formation. Appl. Catal. A. 212, 83-96 (2001). https://doi.org/10.1016/S0926-860X(00)00845-0

40. Teixeira, C.M., Frety, R., Barbosa, C.B.M., Santos, M.R., Bruce, E.D., Pacheco, J.G.A.: Mo influence on the kinetics of jatropha oil cracking over Mo/HZSM-5 catalysts. Catal. Today. 279, 202-208 (2017). https://doi.org/10.1016/j.cattod.2016.06.006

41. Buchanan, J.S.: The chemistry of olefins production by ZSM-5 addition to catalytic cracking units. Catal. Today. 55, 207-212 (2000). https://doi.org/10.1016/S0920-5861(99)00248-5

42. Schmidt, P., Batteiger, V., Roth, A., Weindorf, W., Raksha, T.: Power-to-liquids as renewable fuel option for aviation: A review. Chem. Ing. Tech. 90, 127-140 (2018). https://doi.org/10.1002/cite.201700129

\section{Figures}




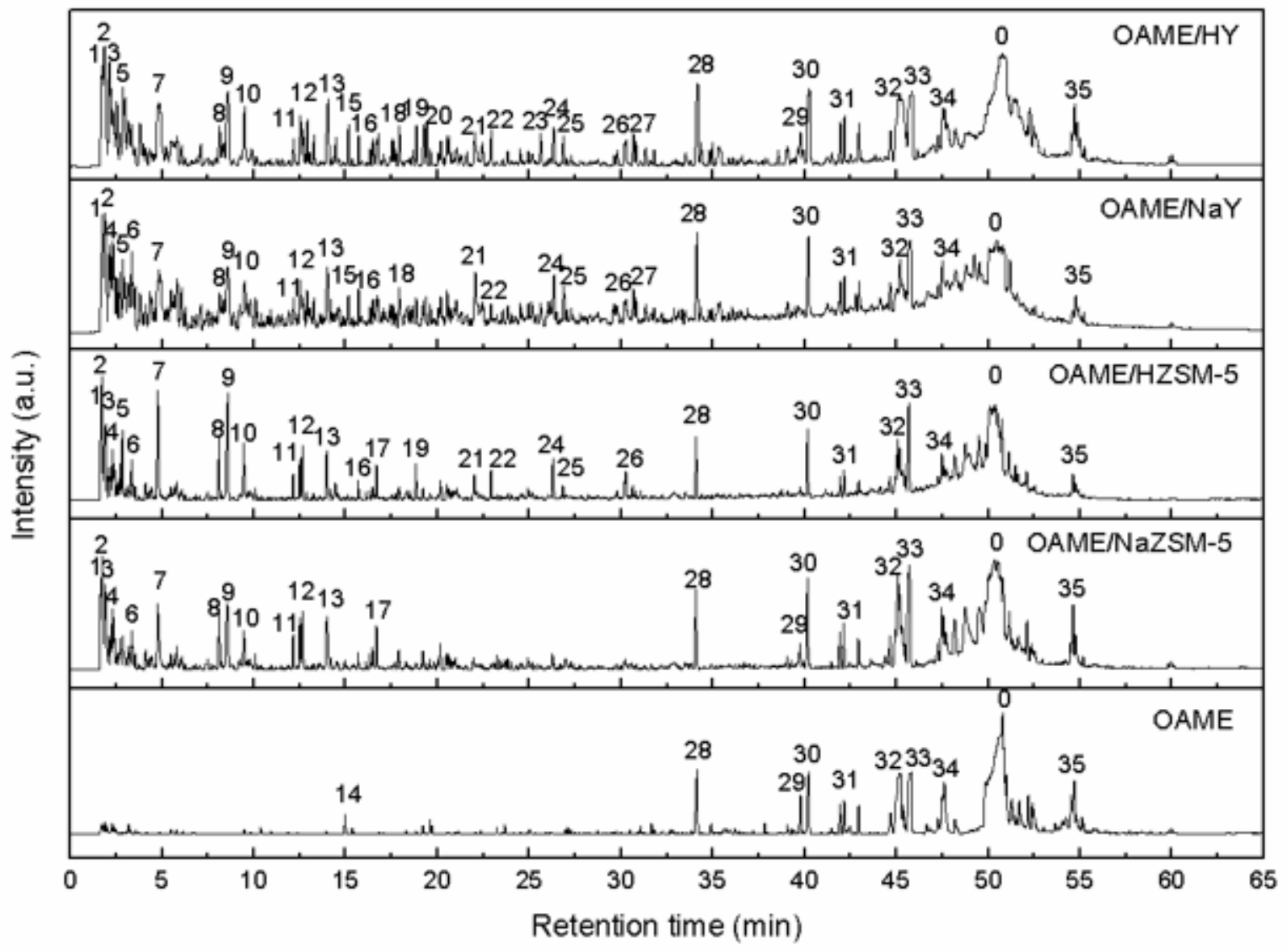

Figure 1

Pyrograms obtained after cracking of oleic acid methyl ester at $650^{\circ} \mathrm{C}$, pure and in the presence of catalysts. Main compounds in pyrograms: (0) oleic acid methyl ester (OAME), (1) propene, (2) butene, (3) pentene, (4) hexene, (5) benzene, (6) 4-methyl-2-hexene, (7) toluene, (8) ethylbenzene, (9) o-xylene, (10) mxylene, (11) propylbenzene, (12) 1-ethyl-2-methylbenzene, (13) 1,2,3-trimethylbenzene, (14) heptanoic acid methyl ester, (15) 1-ethyl-3-methylbenzene, (16) indane, (17) 1,2-diethylbenzene, (18) 1-ethyl-3,5 dimethylbenzene, (19) nonanal, (20) 1,2,3,4-tetramethylbenzene, (21) naphthalene, (22) decanal, (23) 1ethyl-2,4,5-trimethylbenzene, (24) 1-methylnaphthalene, (25) 2-methylnaphthalene, (26) 1,5dimethylnaphthalene, (27) 1,3-dimethylnaphthalene, (28) dodecanoic acid methyl ester, (29) tetradecanoic acid methyl ester, (30) pentadecanoic acid methyl ester, (31) 9-methyltetradecanoic acid methyl ester, (32) 9-hexadecenoic acid methyl ester, (33) hexadecanoic acid methyl ester, (34) heptadecanoic acid methyl ester, (35) 11-eicosenoic acid methyl ester. 


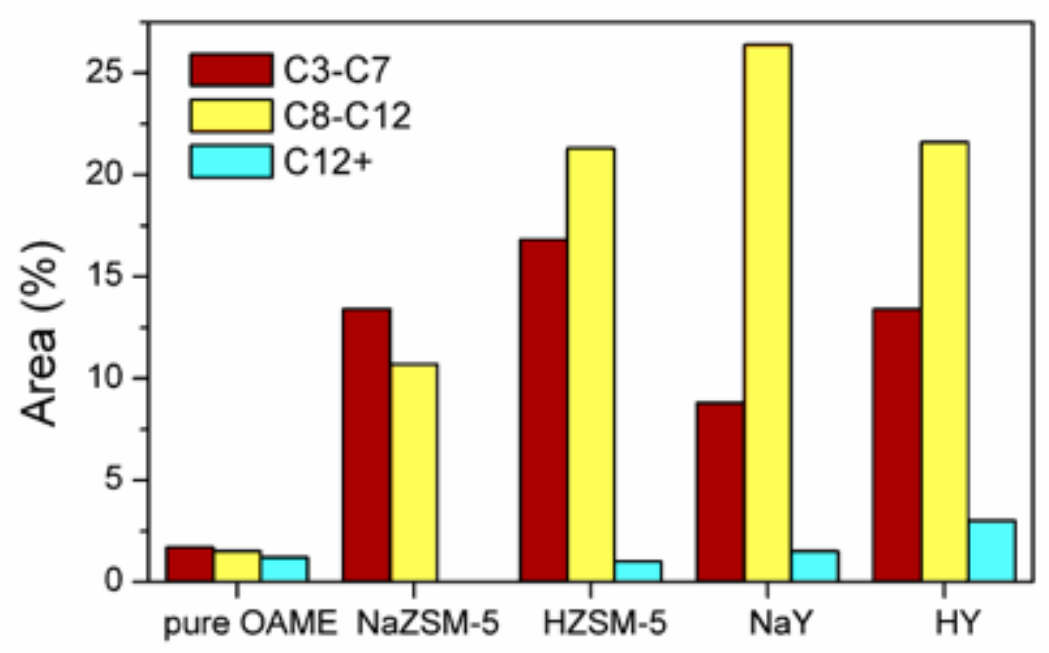

Figure 2

Distribution of deoxygenated products according to carbon number in the $\mathrm{C} 3-\mathrm{C} 7$ (gaseous and gasoline) range, C8-C12 (kerosene) range and $\mathrm{C} 12+$ (diesel) range after cracking at $650{ }^{\circ} \mathrm{C}$ of oleic acid methyl ester (OAME), pure and in presence of NaZSM-5, HZSM-5, NaY and HY catalysts.

\section{Supplementary Files}

This is a list of supplementary files associated with this preprint. Click to download.

- 10AMECrackingGraphicalAbstract.tif 